\title{
Risk factors for mortality among tuberculosis patients on treatment at Bugando Medical Centre in north-western Tanzania: a retrospective cross- sectional study
}

\author{
DANIEL W. GUNDA ${ }^{1,2 *}$, SEMVUA B. KILONZO ${ }^{1,2,}$ SALUM M. BULEGESI', BONAVENTURA C.T. MPONDO³ and \\ ELICHILIA R. SHAO 4 \\ 'Department of Internal Medicine, Weill Bugando School of Medicine, P.O. Box 1464, Mwanza, Tanzania \\ ${ }^{2}$ Department of Internal Medicine, Bugando Medical Centre, P.O. Box 1370 Mwanza Tanzania \\ 3 Department of Internal Medicine, University of Dodoma, Dodoma, Tanzania \\ ${ }^{4}$ Department of Infectious Disease, Kilimanjaro Christian Medical College, Moshi, Tanzania
}

\begin{abstract}
Background: Tuberculosis (TB) is still an important cause of morbidity and mortality worldwide. Though it can effectively be treated, still a significant proportion of patients die on the course of their treatment. The objective of this study was to determine the outcome and risk factors of mortality among patients diagnosed with TB in a tertiary hospital in north-western Tanzania.

Methods: A retrospective cross sectional study was done among all patients diagnosed with TB between January and December 2015 at Bugando Medical Centre. Information of demographic characteristics, smear positivity, haemoglobin concentration, HIV status, CD4 counts for HIV positive patients and treatment outcomes were collected and analysed. TB treatment outcomes as dead or alive were calculated and logistic regression was done to determine the factors associated with increased risk of death of patients on anti-TB treatment.

Results: In total 701 patients were diagnosed with TB during the study period. Of these, $361(51.5 \%)$ were males with a median age of 38 (IQR 27-47) and 421 (60.06\%) were younger than 40 years. Majority of the participants 409 (58.35\%) had smear positive pulmonary tuberculosis and about half of patients (51.07\%) tested positive for HIV. Of the enrolled patients 610 (87.02\%) were alive at the end of TB treatment while $91(12.98 \%)$ died in the course of treatment. The odds of deaths of patients on anti-TB treatment were strongly associated with male sex, HIV co infection and severe anaemia.

Conclusion: The proportion of patients who die from TB treatment at BMC is high, with an increased risk of death among HIV co-infected, older than 40 years and severely anaemic patients. Improvement of strategies for early diagnosis and prompt treatment of TB patients will potentially improve treatment outcome.
\end{abstract}

Keywords: Tuberculosis, treatment, mortality, old age, anaemia, Tanzania

\section{Introduction}

Tuberculosis (TB) is one of the oldest infectious diseases caused by an airoborne bacterium, Mycobacterium tuberculosis with the lungs being the commonest site of infection (Smith 2003; Sakamoto, 2012). About one third of the worlds' population is estimated to be infected with $M$. tuberculosis whereas about 33\% develop active TB (Lonnroth \& Raviglione, 2008), making a global prevalence of active TB of more than 13 million people with African region bearing more than $70 \%$ of the global burden (WHO, 2015). Patients infected with TB frequently present with cough with sputum smear being the most common mode of diagnosis (Sia \& Wieland, 2011; Seni et al., 2012). Smear positive patients are the most infectious ones capable of infecting up to 15 people a year (Sepkowitz, 1996).

Early diagnosis and treatment of smear positive patients is a corner stone for TB control. But even with the availability of potent anti-tuberculous agents, TB still remains as a leading cause of high morbidity and mortality after HIV/AIDS (WHO, 2013). In 2012 about 8.6 million people were newly diagnosed to have TB and 1.3 million died of the disease (WHO 2013), while the 2015 WHO report indicate that 9.6 million people were newly diagnosed with TB globally with mortality of 1.5

*Correspondence E-mail: daniel_rev2002@yahoo.com 
million people (WHO, 2015). Of a note here is that though this increment of TB cases could be because of improved diagnostic abilities but then this means also that more TB cases still remain undiagnosed in the community. The undiagnosed cases in this view are important that they are potential foci of ongoing new transmission and are likely to be diagnosed late at which point they are likely to have poor outcome on their treatment.

The mortality rate due to TB varies widely across the globe with some regions reporting higher rates (Kantipong et al., 2012; WHO, 2015). At Bugando Medical Centre in north-western Tanzania, TB has been reported previously as a cause of morbidity in more than $30 \%$ of the admissions among febrile patients (Meremo et al., 2012). Several factors have been studied previously and reported to be associated with increased likelihood of early TB mortality together with Late diagnosis of TB due to poor health seeking behaviour (Storla et al., 2008; Virenfeldt et al., 2014), advanced age (Amnuaiphon et al., 2009; Horne et al., 2010), HIV co infection (Vijay et al., 2011) and several co morbidities including severe anaemia, liver failure and diabetes mellitus (AlaviNaini et al., 2013). In Tanzania, the information regarding the magnitude and risk factors of this problem is still inadequate. This study was therefore carried out to determine the outcome and risk factors of mortality among patients diagnosed with TB in a tertiary hospital in north-western Tanzania.

\section{Materials and methods}

\section{Study design and population}

This was a retrospective cross-sectional study, involving all patients diagnosed with pulmonary TB and put on standard anti tuberculous treatment Bugando Medical Centre (BMC) between January and December 2015. BMC is a tertiary and teaching hospital in Mwanza, north-western Tanzania. It has a catchment population of more than 16 million people from 8 regions of Tanzania, namely Mara, Mwanza, Geita, Shinyanga, Simiyu, Tabora, Katavi and Kigoma. It has a bed capacity of about 1000 , running both in-patient and out-patient services. Patients diagnosed to have TB either in the inpatient or outpatient department are all registered with the TB clinic for treatment and follow up. About 600-1000 patients are diagnosed with TB every year.

The diagnosis of TB is made according to Tanzanian TB diagnosis algorithm (MoHSW, 2006). All TB suspects undergo sputum examination and on diagnosis HIV testing and counselling is additionally offered and patients get initiated on Anti-TB. Patients who as well test positive for HIV get linked to HIV care and treatment services for treatment and follow up. This study included all patients diagnosed to have TB and started on a 6-month course of anti-tuberculosis treatment at BMC between January 2015 and December 2015.

\section{Sample size, sampling procedure and data collection}

A minimum sample size of 553 was estimated from Leslie Kish formula for cross sectional studies assuming $10 \%$ mortality will occur in TB patients in the course of their treatment (Walpola et al., 2003; Lin et al., 2014). All patients diagnosed with TB during the study period whose data were available in the TB record were included in the study. A TB registry was used to identify patients diagnosed with TB. The patients' identifiers were then used to trace the files at Medical Records Department and at HIV Care and treatment Centre (CTC). The information extracted included age, sex, occupation, past history of TB treatment, smoking, HIV status, outcome of patients on treatment (either dead or alive) and TB treatment duration before death.

\section{Data analysis}

The data were cleaned and entered using Epi info software and analysis was done using STATA 12. All continuous variables were summarized as medians with interquartile range while categorical data were recorded as proportions with percentages. In this study any death occurring during TB treatment was regarded as TB related death as defined by WHO (WHO 2010). The proportion of TB 
patients who died was calculated and the Odds ratios of different factors with $95 \%$ confidence interval were determined using logistic regression model to find out the degree of association between different potential risk factors and the outcome of interest.

\section{Ethical clearance}

The permission to conduct this study and publish the findings was obtained from Bugando Medical Centre/Catholic University of Health and Allied Sciences research and ethical committee. Patients' identifiers like names and file number were not included in the analysis of this study to further maintain confidentiality.

\section{Results}

\section{Baseline characteristics of study participants}

A total of 701 patients were diagnosed to have TB between January and December 2015. Most of the patients $361(51.5 \%)$ were males with a median age of 38 (IQR 27-47) years. About $60 \%(n=421)$ were younger than 40 years. The majority of the study participants $409(58.35 \%)$ had smear positive pulmonary tuberculosis and most patients 358 (51.07\%) tested positive for HIV. The HIV positive

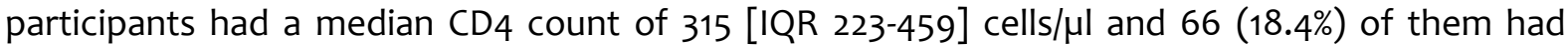
baseline CD4 counts $<200$ cells $/ \mu$ l. (Table 1 ).

Table 1: The basic demographic, clinical and laboratory characteristics of study participants

\begin{tabular}{|c|c|c|c|}
\hline Factor/variable & Response & Frequency & Percent or Median (IQR) \\
\hline \multirow{2}{*}{ Sex } & Male & 361 & 51.50 \\
\hline & Female & 340 & 48.50 \\
\hline \multirow[t]{3}{*}{ Age (years) } & All & 701 & $37.5[27-47]$ \\
\hline & $\geq 40$ & 280 & 39.94 \\
\hline & $<40$ & 421 & 60.06 \\
\hline \multirow[t]{2}{*}{ Smoking } & Yes & 32 & 4.56 \\
\hline & No & 669 & 95.44 \\
\hline \multirow[t]{2}{*}{ TB recurrence } & Yes & 12 & 1.71 \\
\hline & No & 689 & 98.29 \\
\hline \multirow[t]{2}{*}{ Smear results } & Positive & 409 & 58.35 \\
\hline & Negative & 292 & 41.65 \\
\hline \multirow[t]{2}{*}{ HIV testing } & Positive & 358 & 51.07 \\
\hline & Negative & 343 & 48.93 \\
\hline \multirow[t]{3}{*}{ CD4 counts } & All & & $315[223-459]$ \\
\hline & $<200$ Cells $/ \mu \mathrm{l}$ & 66 & 18.4 \\
\hline & $>200$ Cells $/ \mu \mathrm{l}$ & 292 & 81.6 \\
\hline \multirow[t]{3}{*}{ WBC $\left(*_{10}{ }^{\wedge} 3 / \mu \mathrm{l}\right)$} & All & 701 & $4.7[3.7-5.4]$ \\
\hline & $<3.5$ & 123 & 17.55 \\
\hline & $>3.5$ & 578 & 82.45 \\
\hline \multirow[t]{5}{*}{$\mathrm{HB}(\mathrm{g} / \mathrm{dl})$} & All & 701 & $11.7[10.2-13.4]$ \\
\hline & Normal HB (>12/13) & 343 & 48.93 \\
\hline & Mild anaemia(10-12/13) & 202 & 28.82 \\
\hline & Moderate anaemia $(8-10)$ & 98 & 13.98 \\
\hline & Severe anaemia $(<8)$ & 58 & 08.27 \\
\hline \multirow[t]{2}{*}{ Platelet $\left({ }^{*} 10^{\wedge} 3 / \mu \mathrm{l}\right)$} & $<150$ & 44 & 6.28 \\
\hline & $>150$ & 657 & 93.72 \\
\hline \multirow[t]{5}{*}{ TB outcome on treatment } & Died on TB treatment & 91 & 12.98 \\
\hline & HIV positive & 61 & 71.43 \\
\hline & HIV negative & 30 & 28.57 \\
\hline & Alive & 610 & 87.02 \\
\hline & Months on anti-TB & 701 & $2[1-3]$ \\
\hline
\end{tabular}

Key: HB: Haemoglobin; HIV: Human immunodeficiency virus; IQR: Interquartile range; TB: Tuberculosis WBC: White blood cell 
The majority $(87.02 \% ; n=610)$ of the study participants were alive at the end of their TB treatment while $91(12.98 \%)$ of them died during the course of their anti-TB treatment; $61(71.43 \%)$ of these being HIV co infected patients. Three quarters (75\%) of all TB deaths occurred within the first three months of anti-TB treatment with a median time of 2 months on anti-TB drugs before deaths (Figure 1).

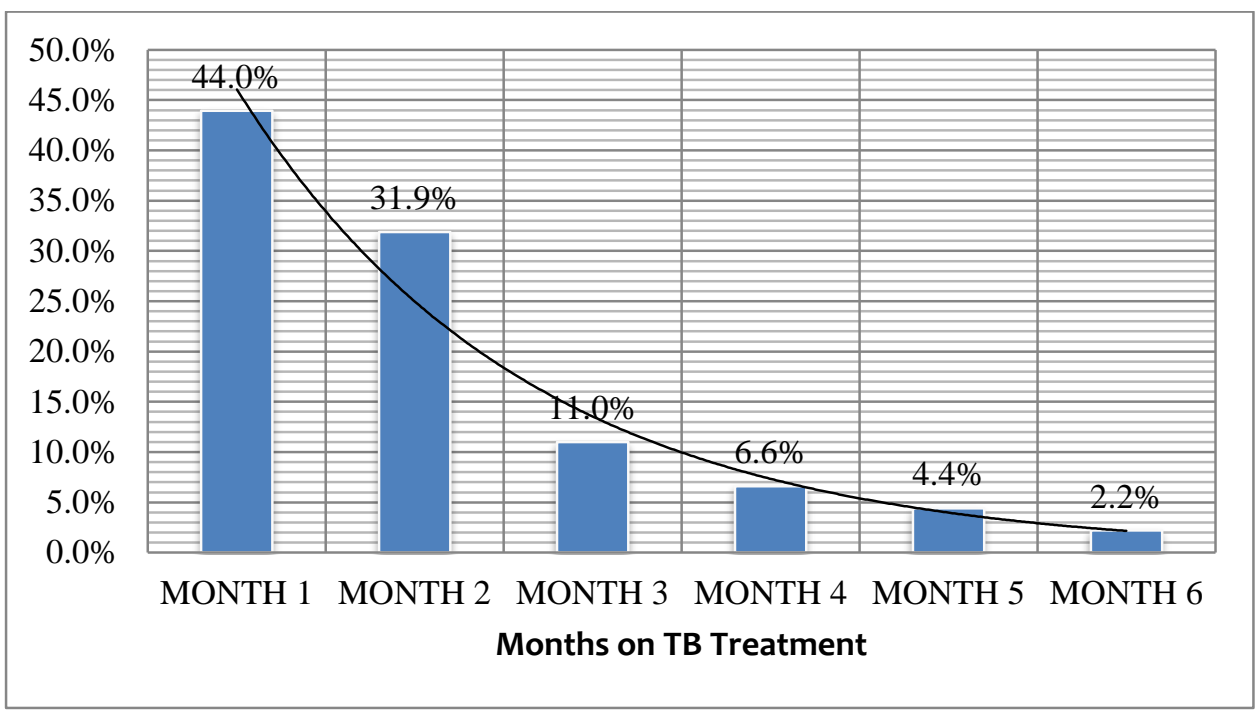

Figure 1: Distribution of death by month on treatment

\section{Factors associated with mortality}

The odds of TB related deaths on univariate analysis were strongly correlated to a male sex $(O R=2.1, p=0.002)$, age older than 40 years $(O R=1.6, p=0.048)$, Smear positive $T B(O R=3.6, p<0.001)$, HIV co infection (OR=2.7, $\mathrm{p}<0.001)$, and severe anaemia $(\mathrm{OR}=3.2, \mathrm{p}<0.001)$. However, on a multivariate analysis only male sex $(\mathrm{OR}=2.2, \mathrm{p}=0.001)$, HIV co infection $(\mathrm{OR}=2.6, \mathrm{p}<0.001)$ and severe anaemia $(O R=2.9, p=0.001)$ remained independently associated with deaths from TB treatment (Table 2). The difference in the distribution of other factors was not statistically significant.

Table 2: Univariate and multivariate analysis for factors related to mortality among TB patients

\begin{tabular}{|c|c|c|c|c|c|c|c|}
\hline Factor & $\begin{array}{l}\text { Response/ } \\
\text { Results }\end{array}$ & $\begin{array}{l}\text { Outcome } \\
\text { treatment }\end{array}$ & TB & Unadjusted & & Adjusted & \\
\hline & & Alive & Dead & OR(95\%Cl) & P-value & OR(95\%Cl) & P-Value \\
\hline \multirow[t]{2}{*}{ Sex } & Male & $300(49.18)$ & $61(67.03)$ & & & & \\
\hline & Female & $310(50.82$ & $30(32.97)$ & $2.1(1.3-3.3)$ & 0.002 & $2.2(1.4-3.4)$ & 0.001 \\
\hline \multirow[t]{2}{*}{ Age (years) } & $\geq 40$ & $235(38.52)$ & $45(49.45)$ & & & & \\
\hline & $<40$ & $375(61.48)$ & $46(50.55)$ & $1.6(1-2.4)$ & 0.048 & $1.3(0.8-2.1)$ & 0.222 \\
\hline \multirow[t]{2}{*}{ Smoking } & Yes & $088(96.70)$ & $03(03.30)$ & & & & \\
\hline & No & $581(95.25)$ & $29(04.75)$ & $0.7(0.2-2.2)$ & 0.537 & & \\
\hline \multirow[t]{2}{*}{ TB recurrence } & Yes & $089(97.80)$ & $02(02.20)$ & & & & \\
\hline & No & $600(98.36)$ & $10(01.64)$ & $1.3(0.3-6.2)$ & 0.703 & & \\
\hline \multirow[t]{2}{*}{ Smear results } & AFB +ve & $355(58.20)$ & $54(59.34)$ & & & & \\
\hline & AFB -ve & $255(41.80)$ & $37(40.66)$ & $3.6(2-6.2)$ & 0.000 & $1.0(0.6-1.6)$ & 0.973 \\
\hline \multirow[t]{2}{*}{ HIV status } & Positive & $293(48.03$ & $61(71.43)$ & & & & \\
\hline & Negative & $317(51.97$ & $26(28.57)$ & $2.7(1.8-4.4)$ & 0.000 & $2.6(1.6-4 \cdot 3)$ & 0.000 \\
\hline \multirow[t]{2}{*}{ Leukopenia } & Yes & $080(87.91)$ & 011 (12.09) & & & & \\
\hline & No & $498(81.64)$ & $112(18.36)$ & $0.6(0.3-1.2)$ & 0.146 & & \\
\hline \multirow[t]{3}{*}{ Anaemia } & Severe & $041(6.72)$ & $17(18.68)$ & $3.2(1.7-5.9)$ & 0.000 & $2.9(1.5-5.6)$ & 0.001 \\
\hline & Moderate & $088(14.4)$ & $10(10.99)$ & $0.7(0.4-1.5)$ & 0.379 & & \\
\hline & Mild & $186(30.49$ & $16(17.58)$ & $0.5(0.3-0.9)$ & 0.013 & & \\
\hline \multirow[t]{2}{*}{ Thrombopenia } & Yes & $086(94.51)$ & $05(05.49)$ & & & & \\
\hline & No & $571(93.61)$ & $39(39.00)$ & $0.9(0.3-2.2)$ & 0.742 & & \\
\hline
\end{tabular}

Key: AFB: Acid fast bacilli; Cl: Confidence interval; HIV: Human immunodeficiency virus; OR: Odds ratio; TB: Tuberculosis 


\section{Discussion}

Of the TB patients diagnosed during the study period, about 13\% died in the course of their TB treatment. The risk factors associated with their deaths were male sex, HIV co infection and severe anaemia. The TB related deaths in our current study are similar to findings of a study in South Africa (Mabunda et al., 2014). However, this rate is higher than that reported previously in a study in Australia (Walpola et al., 2003). This low death rate in Australia is probably attributed to overall low prevalence of TB and HIV. In Australia the national annual TB notification rate is at 4.6 cases per 100,000 population (Lumb et al., 2014). This lower burden of TB infection could as well be accompanied by lower mortality rate from the disease. On the other hand, the rate reported in the index study is much lower than the rates reported from several other studies Taiwan(Lo et al., 2015) and China (Lin et al., 2014).

In Tanzania, a TB related mortality rate of $26.9 \%$ was previously reported among HIV/TB coinfected patients admitted to Muhimbili National Hospital in Dar es Salaam (Kamenju \& Aboud 2011). This higher rate could be due to the reason that this study involved only those TB patients who were admitted to the hospital which represents a sub-group of seriously ill patients. In a recent systematic review determining the cause of death among HIV patients, TB was responsible for more than one-third of all deaths among adult patients (Gupta et al., 2015), where the death rates varied regionally with the highest rate of $63.2 \%$ reported in Asia and the lowest rate of $27.1 \%$ in America while in sub Saharan Africa the death rate was 43.2\%. Additionally, in this study it was found that TB was diagnosed at autopsy in one-third to over half of the patients. This suggests that the lower rates in other reports could partly be due to some percentages of un-diagnosed TB especially in resource limited settings.

Even with these differences one other crucial finding is the similarity in the timing of these deaths. The first two months of anti-TB treatment match with the maximum rate of deaths. More than three-quarters of the deaths occurred within this period in the current study. Similarly, in between $41 \%$ and $46 \%$ of death among TB patients occurred within the first month of treatment in Thailand and Malawi (Harries et al., 2001; Moolphate et al., 2011). On clinical grounds these findings are important that to reduce the rate of mortality among TB patients on treatment probable intervention strategies could be planed around this point of highest rate of mortality. While these high rates of deaths during the first phase of TB treatment could partly be related to advanced stage of TB on diagnosis and a poor tolerance to TB drugs, a number of factors comparable to our findings have been found to increase the risk of deaths including a male sex (Amnuaiphon et al. 2009; Low et al., 2009; Horne et al., 2010; Djouma et al., 2015), older age than 40 years (Amnuaiphon et al., 2009; Low et al., 2009; Horne et al., 2010; Pepper et al., 2015), smear positive PTB (Waitt \& Squire, 2011; Alavi-Naini et al., 2013), HIV co-infection (Horne et al., 2010; Waitt \& Squire, 2011; Djouma et al., 2015; Pepper et al., 2015) and severe anaemia (Alavi-Naini et al., 2013). A female sex (Pepper et al., 2015), smear negative TB and extra pulmonary TB (Djouma et al., 2015), history of smoking, drug hepatitis, diabetes mellitus and history of previous TB (Alavi-Naini et al., 2013) are additional risk factors reported in other studies. The presence of any of these factors could be useful in identifying the at risk patients and plan them on a potential intervention to improve their outcome on treatment.

At older age than 40 years, vulnerability to TB and death is increased. This age group is known to have a disrupted immunity due to ageing process on top of co-morbidities like chronic obstructive pulmonary diseases (Negin et al., 2015). Based on this the TB presentation is often atypical (Dahmash et al., 1995) usually confused with age related illnesses (Tan et al., 1991; Yoshikawa, 1992) and difficult to diagnose by conventional methods. The diagnosis is then most of the time delayed at stages that are more advanced with fatal outcome (Yoshikawa, 1992; Cantalice Finlo et al., 2007; Negin et al., 2015) and most elderly patients may therefore die undiagnosed (Yoshikawa, 1992). Use of constitutional symptoms like wasting and drenching nights (Cantalice 
Finlo et al., 2007) may be helpful in supporting early identification and prompt treatment of these potential elderly with TB to improve their outcome around these possible diagnostic challenges.

The anaemia in TB patient is often of low mean corpuscular volume $(\mathrm{MCV})<8 \mathrm{ofl}$ which is either iron deficiency or from a chronic inflammatory process (Isanaka et al., 2012; Oliveira et al., 2014). Both of these situations make iron un-available for most biological functions including its role in cell mediated immunity. Iron deficiency may decrease T-cell numbers by reducing the proliferative response and potentially dropping the macrophage activity (Dallman 1987; Oppenheimer, 2001) increasing morbidity and mortality from most infections. A previous study in Tanzania had indicated that iron deficiency anaemia was associated with 2-3 fold risk of death among TB patients (Isanaka et al., 2012), and a study from Korea had shown that up to one-third had anaemia on diagnosis (Lee et al., 2006), which significantly improved with TB treatment. Some studies have indicated a haematological improvement with smear conversion (Morris et al., 1989; Das et al., 2003) suggesting that early diagnosis and prompt treatment of TB could potentially reduce the morbidity and mortality from anaemia.

$\mathrm{TB}+\mathrm{HIV}$ co infection being the commonest co infections carry an increasingly high mortality (Akksilp et al., 2007; Vijay et al., 2011). On TB treatment the mortality is especially high among patients who are not on ART (Akksilp et al., 2007; Sileshi et al., 2013), those with low CD4 counts (Bhowmik et al., 2012; Sileshi et al., 2013) and not being on cotrimoxazole prophylaxis (Sileshi et al., 2013). This information supports a routine screening of HIV among all TB infected patients and early initiation of ART and cotrimoxazole prophylaxis could potentially reduce the mortality of TB patients on treatment.

This study had a number of limitations. The study was a single centre study; the results from this study may not necessarily be generalizable. The cause of death among this sub group of patients could not be established because autopsy was not done. Being a retrospective study, missing data for some patients was also a limitation. All in all, the findings of this study will add some knowledge on the magnitude of mortality and the factors associated with mortality due to TB. In conclusion, the proportion of patients who die at the early stage of TB treatment is still high in Tanzania with an increased risk of death among HIV co-infected, males and severely anaemic patients. Improvement of strategies for early diagnosis and prompt treatment of TB patients will potentially improve treatment outcome of TB patients.

\section{Acknowledgements}

We would like to acknowledge the assistance given by the TB/HIV clinical and medical record staff members during data collection. We also acknowledge the support of BMC CTC staff during this study.

\section{Authors' contribution}

DWG SMB SBK designed the study and prepared the study protocol; SMB DWG collected the data; DWG SBK BCP analyzed and interpreted the data, DWG SMB did literature search and drafted the manuscript; SBK MCP ERS critically reviewed the manuscript for its intellectual content. All authors approved the last version before submission. 


\section{Conflict of interest}

The authors have no conflict of interest to declare.

\section{References}

Akksilp, S., Karnkawinpong, O., Wattanaamornkiat, W., Viriyakitja, D., Monkongdee, P., Sitti, W., Rienthong, D., Siraprapasiri, T., Charles D. Wells C.D., Tappero, J.W. \& Varma J.K. (2007) Antiretroviral therapy during tuberculosis treatment and marked reduction in death rate of HIV-infected patients, Thailand. Emerging Infectious Diseases 13, 1001-1007.

Alavi-Naini, R., Moghtaderi, A., Metanat, M., Mohammadi, M. \& Zabetian, M. (2013) Factors associated with mortality in tuberculosis patients. Journal of Research in Medical Sciences $18,52-55$.

Amnuaiphon, W., Anuwatnonthakate, A., Nuyongphak, P., Sinthuwatanawibool, C., Rujiwongsakorn, S., Nakara, P., Komsakorn, S., Wattanaamornkiet, W., Moolphate, S., Chiengsorn, N., Kaewsaard, S., Nateniyom, S. \& Varma, J.K. (2009) Factors associated with death among HIV-uninfected TB patients in Thailand, 2004-2006. Tropical Medicine and International Health 14, 1338-1346.

Bhowmik, A., Bhandari, S., De, R. \& Guha, S.K. (2012) Predictors of mortality among HIV-infected patients initiating anti retroviral therapy at a tertiary care hospital in eastern India. Asian Pacific Jouranl of Tropical Medicine 5, 986-990.

Cantalice Filho, J.P., Sant Anna, C.C. \& Neves Bóia, M. (2007) Clinical aspects of pulmonary tuberculosis in elderly patients from a university hospital in Rio de Janeiro, Brazil. Journal of Brasilian Pneumology 33, 699-706.

Dahmash, N.S., Fayed D.F., Chowdhury, M.N.H. \& Arora, S.C. (1995) Diagnostic challenge of tuberculosis of the elderly in hospital: experience at a university hospital in Saudi Arabia. Journal of Infection 31, 93-97.

Dallman, P.R. (1987) Iron deficiency and the immune response. Amercan Journal of Clinical Nutrition 46, 329-334.

Das, B.S., Devi, U., Rao, C. M.,Srivastava, V.K., Rath, P.K. \& Das, B.S. (2003) Effect of iron supplementation on mild to moderate anaemia in pulmonary tuberculosis. British Journal of Nutrition 90, 541-550.

Djouma, F.N., Noubom, M., Ngomba, A.V., Donfack, H., Kouomboua, P.S. \& Saah, M.A. (2015) Determinants of death among tuberculosis patients in a semi urban diagnostic and treatment centre of Bafoussam, West Cameroon: a retrospective case-control study. Pan African Medical Journal 22, 253.

Gupta, R.K., Lucas, S.B., Fielding, K.L. \& Lawn, S.D. (2015) Prevalence of tuberculosis in postmortem studies of HIV-infected adults and children in resource-limited settings: a systematic review and meta-analysis. AIDS 29, 1987-2002.

Harries, A.D., Hargreaves, N.J., Gausi, F., Kwanjana, J.H. \& Salaniponi, F.M. (2001) High early death rate in tuberculosis patients in Malawi. International Journal of Tuberculosis and Lung Diseases 5, 1000-1005.

Horne, D.J., Rebecca Hubbard, R., Masahiro Narita, M., Exarchos, A., David R Park, D.R. \& Goss, C.H. (2010) Factors associated with mortality in patients with tuberculosis. BioMedical Central Infectious Diseases 10: 258.

Isanaka, S., Mugusi, F., Urassa, W., Willett, C.W., Bosch, R.J., Villamor, E., Donna Spiegelman, D., Duggan, C. \& Fawzi, W.W. (2012) Iron deficiency and anemia predict mortality in patients with tuberculosis. Journal of Nutrition 142, 350-357.

Kamenju, P. \& Aboud, S. (2011) Tuberculosis-HIV co-infection among patients admitted at Muhimbili National Hospital in Dar es salaam, Tanzania. Tanzania Journal of Health Research 13, 21-26. 
Kantipong, P., Murakami, K., Moolphate, S., Aung M. N. \& Yamada, N. (2012) Causes of mortality among tuberculosis and HIV co-infected patients in Chiang Rai, Northern Thailand. HIV AIDS Research and paliative care (Auckl) 4: 159-168.

Lee, S.W., Kang, Y.A., Yoon, Y.S., Um, S.W., Lee, S.M., Yoo, C.G., Kim, Y.W., Han, S.K., Shim, Y. S. \& Yim, J.J. (2006) The prevalence and evolution of anemia associated with tuberculosis. Journal of Korean Medical Sciences 21, 1028-1032.

Lin, C.H., Lin, C.J., Kuo, Y.W., Wang, J.Y., Hsu, C.L., Chen, J.M., Cheng, W.C. \& Lee, L.N. (2014) Tuberculosis mortality: patient characteristics and causes. BioMedical Central Infectious Diseases 14: 5 .

Lo, H.Y., Suo, J., Chang, H.J., Yang, S.L. \& Chou, P. (2015) Risk factors associated with death in a 12month cohort analysis of tuberculosis patients: 12-month follow-up after registration. Asia Pacific Journal of Public Health 27, 758-768.

Lonnroth, K. \& Raviglione, M. (2008) Global epidemiology of tuberculosis: prospects for control. Seminars in Respiratory and Critical Care Medicine 29, 481-491.

Low, S., Ang, L.W., Cutter, J., James, L., Chee, C.B., Wang, Y.T. \& Chew, S.K. (2009) Mortality among tuberculosis patients on treatment in Singapore. Internation Journal of Tuberculosis and Lung Diseases 13, 328-334.

Lumb, R., Bastian, I.B., Jelfs, P.J., Keehner, T.J., Pandey, S.K. \& Sievers, A. (2014) Tuberculosis in Australia: bacteriologically-confirmed cases and drug resistance, 2011. A report of the Australian Mycobacterium Reference Laboratory Network. Communicalble Diseases Intelligence Quarterly Report 38, E369-375.

Mabunda, T.E., Ramalivhana, N.J. \& Dambisya, Y.M. (2014) Mortality associated with tuberculosis/HIV co-infection among patients on TB treatment in the Limpopo province, South Africa. African Health Science 14, 849-854.

Meremo, A.J., Kidenya, B.E., Mshana, S.E., Kabangila, R. \& Kataraihya, J.B. (2012) High prevalence of tuberculosis among adults with fever admitted at a tertiary hospital in north-western Tanzania. Tanzania Journal of Health Research 14, 183-188.

MoHSW (2006) Manual of the National Tuberculosis and Leprosy Programme in Tanzania. https://aidsfree.usaid.gov/sites/default/files/tb_tanzania_2006'.pdf

Moolphate, S., Aung, M.N., Nampaisan, O., Nedsuwan, S., Kantipong, P., Suriyon, N., Hansudewechakul, C., Yanai, H., Yamada, N. \& Ishikawa, N. (2011) Time of highest tuberculosis death risk and associated factors: an observation of 12 years in Northern Thailand. International Journal of General Medicine 4: 181-190.

Morris, C.D., Bird, A.R. \& Nell, H. (1989) The haematological and biochemical changes in severe pulmonary tuberculosis. Quarterly Journal of Medicine 73, 1151-1159.

Negin, J., Abimbola, S. \& Marais, B.J. (2015) Tuberculosis among older adults--time to take notice. International Journal of Infectious Diseases 32, 135-137.

Oliveira, M.G., Delogo, K.N., Oliveira, H.M., Ruffino-Netto, A., Kritski, A.L. \& Oliveira, M.M. (2014) Anemia in hospitalized patients with pulmonary tuberculosis. Journal of Brasilian Pneumolology 40, 403-410.

Oppenheimer, S.J. (2001) Iron and its relation to immunity and infectious disease. Journal of Nutrition 131, 616S-633S.

Pepper, D.J., Schomaker, M., Wilkinson, J.R., Azevedo, V. \& Maarte, G. (2015) Independent predictors of tuberculosis mortality in a high HIV prevalence setting: a retrospective cohort study." AIDS Research and Therapy 12: 35.

Sakamoto, K. (2012) The pathology of Mycobacterium tuberculosis infection. Veterinary Pathology 49, 423-439.

Seni J., Kidenya, B.E., Obassy, E., Mirambo, M., Burushi, V., Mazigo, H.D., Kapesa, A., Majigo, M. \& Mshana, S.E. (2012) Low sputum smear positive tuberculosis among pulmonary tuberculosis suspects in a tertiary hospital in Mwanza, Tanzania. Tanzania Journal of Health Research 14, 115-120. 
Sepkowitz, K.A. (1996) How contagious is tuberculosis? Clinical Infectious Diseases 23, 954-962.

Sia, I. G. \& Wieland, M.L. (2011) Current concepts in the management of tuberculosis. Mayo Clinic Proceedings $86,348-361$.

Sileshi, B., Deyessa, N., Girma, B., Melese, M. \& Suarez, P. (2013) Predictors of mortality among TBHIV Co-infected patients being treated for tuberculosis in Northwest Ethiopia: a retrospective cohort study. BioMedical Central Infectious Diseases 13: 297.

Smith, I. (2003) Mycobacterium tuberculosis pathogenesis and molecular determinants of virulence. Clinical Microbiology Reviews 16, 463-496.

Storla, D.G., Yimer, S. \& Bjune, G.A. (2008) A systematic review of delay in the diagnosis and treatment of tuberculosis. BioMedical Central Public Health 8: 15.

Tan, K.K., Cherian, A. \& Teo, S.K. (1991) Tuberculosis in the elderly. Singapore Medical Journal 32, 423-426.

Vijay, S., Kumar, P., Chauhan, L.S., Rao, S.V.N. \& Vaidyanathan, P. (2011) Treatment outcome and mortality at one and half year follow-up of HIV infected TB patients under TB control programme in a district of South India. PLoS One 6(7): e21008.

Virenfeldt, J., Rudolf, F., Camara, C., Furtado, A., Gomes, V., Aaby, P., Petersen, E. \& Wejse, C. (2014) Treatment delay affects clinical severity of tuberculosis: a longitudinal cohort study. BMJ Open 4(6): e004818.

Waitt, C.J. \& Squire, S.B. (2011) A systematic review of risk factors for death in adults during and after tuberculosis treatment. International Journal of Tuberculosis and Lung Diseases 15, 871885.

Walpola, H.C., Siskind, V., Patel, A.M., Konstantinos, A. \& Derhy, P. (2003) Tuberculosis-related deaths in Queensland, Australia, 1989-1998: characteristics and risk factors. International Journal of Tuberculosis and Lung Diseases 7, 742-750.

WHO (2010) Guidelines for treatment of tuberculosis fourth Edition. http://apps.who.int/iris/bitstream/10665/44165/1/9789241547833_eng.pdf?ua=1]

WHO (2013) Global Tuberculosis 2013. http://apps.who.int/iris/bitstream/10665/91355/1/9789241564656_eng.pdf

WHO (2015) Global 2015. http://apps.who.int/iris/bitstream/10665/191102/1/9789241565059_eng.pdf?ua=1

Yoshikawa, T.T. (1992) Tuberculosis in aging adults. Journal of Amercan Geriatric Society 40, 178187. 